\title{
ON FIRMLY NONEXPANSIVE MAPPINGS
}

\author{
RYSZARD SMARZEWSKI
}

(Communicated by Palle E. T. Jorgensen)

\begin{abstract}
It is shown that any $\lambda$-firmly, $0<\lambda<1$, nonexpansive mapping $T: C \rightarrow C$ has a fixed point in $C$ whenever $C$ is a finite union of nonempty, bounded, closed convex subsets of a uniformly convex Banach space.
\end{abstract}

Let $C$ be a nonempty subset of a Banach space $X$, and let $\lambda \in(0,1)$. Then a mapping $T: C \rightarrow X$ is said to be $\lambda$-firmly nonexpansive if

$$
\|T x-T y\| \leq\|(1-\lambda)(x-y)+\lambda(T x-T y)\|
$$

for all $x, y \in C$. In particular, if (1) holds for every $\lambda \in(0,1)$, then $T$ is said to be firmly nonexpansive. It is clear that every $\lambda$-firmly nonexpansive mapping is nonexpansive; i.e., for each $x$ and $y$ in $C$, we have $\|T x-T y\| \leq$ $\|x-y\|$. Conversely, to each nonexpansive $T: C \rightarrow C$ one can associate a firmly nonexpansive mapping with the same fixed-point set whenever $C$ is closed and convex [3]. Moreover, from the point of view of fixed-point theory for the class of all closed convex subsets $C$, firmly nonexpansive mappings $T: C \rightarrow$ $C$ do not exhibit better behavior than nonexpansive mappings in general [2]. However, this behavior is completely different in the class of nonconnected subsets $C$. Indeed, in this note we prove the following result:

Theorem. Let $X$ be a uniformly convex Banach space, let $C=\bigcup_{k=1}^{n} C_{k}$ be a union of nonempty, bounded, closed convex subsets $C_{k}$ of $X$, and suppose $T: C \rightarrow C$ is $\lambda$-firmly nonexpansive for some $\lambda \in(0,1)$. Then $T$ has a fixed point in $C$.

This theorem is no longer true if $T$ is merely nonexpansive, even in onedimensional space $X=\mathbb{R}$. For example, if $C=[-2,-1] \cup[1,2]$, then the mapping $T: C \rightarrow C$ defined by $T x=-x$ is nonexpansive and fixed-point free. On the other hand, if $C_{1}=\cdots=C_{n}=C$, then the theorem is true for each nonexpansive mapping $T: C \rightarrow C$, which is the celebrated result of Browder [1], Göhde [4], and Kirk [5]. More generally, the same result is also valid when $\bigcap_{k=1}^{n} C_{k} \neq \varnothing[6]$.

Received by the editors April 23, 1990.

1980 Mathematics Subject Classification (1985 Revision). Primary 47H09, 47H10.

Key words and phrases. Firmly nonexpansive mappings, fixed-point theorems, nonconnected domains. 
Proof of the theorem. Let $z \in C$, and let $x_{k}$ be the unique asymptotic center [3] of sequence $\left(T^{i} z\right)$ with respect to the bounded, closed convex subset $C_{k}$ $(1 \leq k \leq n)$. In other words, by the uniform convexity of $X$, the point $x_{k} \in C_{k}$ is uniquely determined by the identity

$$
f\left(x_{k}\right)=\inf _{x \in C_{k}} f(x),
$$

where the convex functional $f: X \rightarrow[0, \infty)$ is defined by

$$
f(x)=\limsup _{i \rightarrow \infty}\left\|x-T^{i} z\right\| .
$$

Since $T$ is nonexpansive, we have $\left\|T x_{k}-T^{i+1} z\right\| \leq\left\|x_{k}-T^{i} z\right\|$. Hence

$$
f\left(T x_{k}\right) \leq f\left(x_{k}\right)
$$

for all $k$. Now, if $T x_{k} \in C_{k}$ for some $k$, then the uniqueness of asymptotic center $x_{k}$ in conjunction with (2) and (3) yields $T x_{k}=x_{k}$, which completes the proof. Otherwise, if $T x_{k} \notin C_{k}$ for all $k$, then there exist integers $\left\{n_{1}, n_{2}, \ldots, n_{m}\right\} \subset\{1,2, \ldots, n\} \quad(m \geq 2)$ such that $T x_{n_{k}} \in C_{n_{k+1}}(k=$ $1, \ldots, m-1)$ and $T x_{n_{m}} \in C_{n_{1}}$. Clearly, without loss of generality, one can rearrange the sequence $C_{k}$ in such a way that $n_{k}=k$ for all $k$. Then we have $T x_{k} \in C_{k+1}(k=1,2, \ldots, m-1), T x_{m} \in C_{1}$, and $x_{k} \in C_{k}$ for all $k$. Hence, one can combine (2) and (3) in order to get

$$
\begin{aligned}
f\left(x_{1}\right) & \leq f\left(T x_{m}\right) \leq f\left(x_{m}\right) \leq f\left(T x_{m-1}\right) \\
& \leq f\left(x_{m-1}\right) \leq \cdots \leq f\left(x_{2}\right) \leq f\left(T x_{1}\right) \leq f\left(x_{1}\right) .
\end{aligned}
$$

Thus we have $f\left(T x_{k}\right)=f\left(x_{k+1}\right)$ which, in view of the uniqueness of asymptotic centers $x_{k}$, yields

$$
x_{k+1}=T x_{k} \quad(k=1,2, \ldots, m),
$$

where we have denoted $x_{m+1}=x_{1}$ for the latter simplicity. Hence we readily derive

$$
\left\|x_{k-1}-x_{k}\right\|=\left\|T x_{k}-T x_{k+1}\right\| \leq\left\|x_{k}-x_{k+1}\right\|=\left\|T x_{k-1}-T x_{k}\right\| \leq\left\|x_{k-1}-x_{k}\right\|
$$

for every $k$, and

$$
\left\|x_{1}-x_{2}\right\|=\left\|x_{2}-x_{3}\right\|=\cdots=\left\|x_{m-1}-x_{m}\right\|=\left\|x_{1}-x_{m}\right\|:=\gamma .
$$

Clearly, if $\gamma=0$, then $x_{1}=x_{2}=T x_{1}$ by (4). Hence the proof is completed in this case. Thus it remains to show that the inequality $\gamma>0$ is impossible. Since $T$ is $\lambda$-firmly nonexpansive for some $\lambda \in(0,1)$, it follows from (4) that

$$
\begin{aligned}
\gamma & =\left\|x_{k+1}-x_{k}\right\|=\left\|T x_{k}-T x_{k-1}\right\| \leq\left\|(1-\lambda)\left(x_{k}-x_{k-1}\right)+\lambda\left(x_{k+1}-x_{k}\right)\right\| \\
& \leq(1-\lambda)\left\|x_{k}-x_{k-1}\right\|+\lambda\left\|x_{k+1}-x_{k}\right\|=\gamma .
\end{aligned}
$$

Therefore, in view of strict convexity of the norm, we get

$$
x_{k}-x_{k-1}=\alpha_{k}\left(x_{k+1}-x_{k}\right) \quad\left(2 \leq k \leq m, x_{m+1}=x_{1}\right),
$$


for some $\alpha_{k} \neq 0$. Moreover, by (5) we have $\left|\alpha_{k}\right|=1$ for all $k$. Hence the following two cases may occur:

Case I. If $\alpha_{k}=-1$ for some $k$, then $x_{k-1}=x_{k+1}$. Hence one can apply (1) and (4) to get

$$
\begin{aligned}
\left\|x_{k}-x_{k-1}\right\| & =\left\|T x_{k-1}-T x_{k}\right\| \leq\left\|(1-\lambda)\left(x_{k-1}-x_{k}\right)+\lambda\left(x_{k}-x_{k-1}\right)\right\| \\
& =|1-2 \lambda|\left\|x_{k}-x_{k-1}\right\|<\left\|x_{k}-x_{k-1}\right\| .
\end{aligned}
$$

This contradiction shows that $\gamma=0$.

Case II. If $\alpha_{k}=1$ for all $k$, then we have

$$
\begin{gathered}
x_{2}=\left(x_{1}+x_{3}\right) / 2, \quad x_{3}=\left(x_{2}+x_{4}\right) / 2, \ldots, x_{m-1}=\left(x_{m-2}+x_{m}\right) / 2, \\
x_{m}=\left(x_{1}+x_{m-1}\right) / 2 .
\end{gathered}
$$

Clearly, the first $m-2$ identities mean that the points $x_{2}, x_{3}, \ldots, x_{m-1}$ divide the interval $\left[x_{1}, x_{m}\right]$ into $m-1$ subintervals $\left[x_{k}, x_{k+1}\right](1 \leq k \leq m-1)$ of the same length $\gamma>0$. But this leads to a contradiction with the identity $x_{m}=\left(x_{1}+x_{m-1}\right) / 2$. Hence we have always $\gamma=0$, which completes the proof.

\section{REFERENCES}

1. F. E. Browder, Nonexpansive nonlinear operators in a Banach space, Proc. Nat. Acad. Sci. 54 (1965), 1041-1044.

2. K. Goebel and W. A. Kirk, Topics in metric fuxed point theory, Cambridge University Press, Cambridge, 1990.

3. K. Goebel and S. Reich, Uniform convexity, hyperbolic geometry, and nonexpansive mappings, Marcel Dekker, New York, 1984.

4. D. Göhde, Zum Prinzip der kontraktiven Abbildung, Math. Nachr. 30 (1965), 251-258.

5. W. A. Kirk, A fixed point theorem for mappings which do not increase distances, Amer. Math. Monthly 72 (1965), 1004-1006.

6. J. Reinnermann and R. Schöneberg, Some results and problems in the fixed point theory for nonexpansive and pseudocontractive mappings in Hilbert space, Fixed Point Theory Appl. (Srinivasa Swaminathan, ed.) (Proc. Semin. Halifax, 1975), Academic Press, New York, 1976, pp. 187-196.

Department of Mathematics, M. Curie-Skiodowska University, 20-031 Lublin, Poland

Current address: Department of Applied Mathematics, National Chung-Hsing University, Taichung, Taiwan, 40227 R.O.C. 